University of Nebraska - Lincoln

DigitalCommons@University of Nebraska - Lincoln

Faculty Publications, Department of Psychology

Psychology, Department of

2010

\title{
Adult coping with childhood sexual abuse: A theoretical and empirical review
}

\author{
Kate Walsh \\ University of Nebraska-Lincoln \\ Michelle A. Fortier \\ University of California \\ David DiLillo \\ University of Nebraska-Lincoln, ddilillo@unl.edu
}

Follow this and additional works at: https://digitalcommons.unl.edu/psychfacpub

Part of the Psychiatry and Psychology Commons

Walsh, Kate; Fortier, Michelle A.; and DiLillo, David, "Adult coping with childhood sexual abuse: A theoretical and empirical review" (2010). Faculty Publications, Department of Psychology. 396.

https://digitalcommons.unl.edu/psychfacpub/396

This Article is brought to you for free and open access by the Psychology, Department of at DigitalCommons@University of Nebraska - Lincoln. It has been accepted for inclusion in Faculty Publications, Department of Psychology by an authorized administrator of DigitalCommons@University of Nebraska - Lincoln. 


\title{
Adult coping with childhood sexual abuse: A theoretical and empirical review
}

\author{
Kate Walsh, ${ }^{1}$ Michelle A. Fortier, ${ }^{2}$ and David DiLillo ${ }^{1}$ \\ ${ }^{1}$ University of Nebraska - Lincoln, United States \\ ${ }^{2}$ University of California-Irvine and Children's Hospital of Orange County, United States \\ Corresponding author - D, DiLillo, Department of Psychology, \\ University of Nebraska - Lincoln, 238 Burnett Hall, \\ Lincoln, NE, 68588-0308, USA; email ddilillo@unl.edu
}

\begin{abstract}
Coping has been suggested as an important element in understanding the long-term functioning of individuals with a history of child sexual abuse (CSA). The present review synthesizes the literature on coping with CSA, first by examining theories of coping with trauma, and, second by examining how these theories have been applied to studies of coping in samples of CSA victims. Thirty-nine studies were reviewed, including eleven descriptive studies of the coping strategies employed by individuals with a history of CSA, eighteen correlational studies of the relationship between coping strategies and long-term functioning of CSA victims, and ten investigations in which coping was examined as a mediational factor in relation to long-term outcomes. These studies provide initial information regarding early sexual abuse and subsequent coping processes. However, this literature is limited by several theoretical and methodological issues, including a failure to specify the process of coping as it occurs, a disparity between theory and research, and limited applicability to clinical practice. Future directions of research are discussed and include the need to understand coping as a process, identification of coping in relation to adaptive outcomes, and considerations of more complex mediational and moderational processes in the study of coping with CSA.
\end{abstract}

Keywords: childhood sexual abuse, coping strategies, childhood trauma, adult female victims, methods of coping

\section{Introduction}

Estimates suggest that between one-fifth and one-third of females in the U.S. experience some form of sexual abuse during childhood (Elliott and Briere, 1995; Finkelhor, 1994; Finkelhor et al., 1990), although rates within clinical populations of women tend to be much higher (Goodman et al., 1997; Jacobsen and Herald, 1990; Mitchell et al., 1996; Read, 1997). As part of the broader increased 
awareness of CSA, researchers have focused considerable attention on mental health and behavioral outcomes associated with early abuse. This work suggests that CSA is a risk factor for the development of an array of long-term difficulties, including depression, posttraumatic stress, dissociation, and substance abuse (Fergusson et al., 2008; Neumann et al., 1996; Polusny and Follette, 1995).

Although the detrimental correlates of CSA are common, both the short- and long-term outcomes are variable and inconsistent. For example, it has been proposed that $10 \%$ to $25 \%$ of CSA victims report no psychological difficulties in childhood (Conte and Berliner, 1988; Kendall-Tackett et al., 1993). Similarly, studies of long-term outcomes consistently show a significant proportion of victims (20\% to $40 \%)$ report little to no symptomatology as adults (Finkelhor, 1990). This finding fits with recent literature showing that resilience is the most common response to trauma (Bonanno, 2005). Furthermore, among adults, CSA has been linked to such a wide array of psychopathology that some consider it to be a "nonspecific risk factor" for the range of detrimental outcomes seen in CSA victims (Putman, 2003; Romans et al., 1997).

This variation in the degree and range of long-term correlates highlights the need to understand the various intervening processes that may contribute to the diverse outcomes associated with CSA. One obvious source of variation is the nature and severity of the abuse experience itself. Indeed, factors such as the types of acts committed, use of physical force, and the relationship of the victim to the perpetrator each may play important roles determining victims' long-term functioning (Beitchman et al., 1992; Bennett et al., 2000; Elliott and Briere, 1992; Trickett et al., 1997). In addition to abuse-specific characteristics, a number of other factors also may predict post-abuse adjustment as adults including family characteristics such as cohesion and conflict (McClure, Chavez, Agars, Peacock, \& Matosian, 2008) and responses of others upon disclosure of abuse (Wyatt \& Mickey, 1987).

The coping strategies employed by victims represent another potential determinant of the variation in long-term functioning reported by victims. Specifically, individuals who have more adaptive means of managing their abuse-related negative emotions may experience less long-term distress than those who have greater difficulty processing such emotions. In this vein, coping methods often are categorized as effective (e.g., directly addressing a problem) or ineffective (e.g., avoidance), although the effectiveness of certain methods also may be dependent upon the nature of the stressor and time employed (Coyne \& Racioppo, 2000). In light of research showing that coping strategies have been found to impact later adjustment and functioning (Folkman \& Lazarus, 1980), it is reasonable to hypothesize that variability in coping strategies would help to account for the wide range of emotional and behavioral outcomes associated with a history of CSA.

Research and theoretical writings addressing associations between CSA, coping, and long-term functioning have increased dramatically in recent years. One reason for this upsurge may be recognition that coping strategies are amenable to change and thus represent viable targets for intervention among individuals dealing with the negative sequelae of abuse. Despite increased interest in coping and CSA, few attempts have been made to synthesize empirical findings at the intersection of these important areas of research. The primary purpose of this review is to provide a clearer picture of current knowledge about the types of coping used by CSA victims as well as associations between coping and long-term psychological functioning. Through critical examination of this literature, we also offer suggestions for advancing research in the area. As a theoretical backdrop for this review, we first present a brief overview of general coping theory. Because the preponderance of studies has focused on adult victims who are asked either to report about current coping strategies or to provide retrospective accounts of childhood coping, the present review is limited to this area of the literature.

\section{Coping theory}

\subsection{Conceptual overview of coping}

Coping refers to a range of diverse cognitions and behaviors used to manage the internal and external demands of a stressful or threatening situation (Folkman and Lazarus, 1980; Lazarus and Folkman, 1984). Although coping strategies have been identified and categorized along a variety of dimensions (Cohen, 1987; Holohan and Moos, 1987; Roth and Cohen, 1986), one common approach classifies coping as consisting of either cognitive or behavioral responses to a specific stressor or situation (Holohan \& Moos, 1987). Cognitive coping strategies include attempts to change one's perception or conception of a situation, whereas behavioral coping includes actions taken to reduce the effects of stress. For example, focusing on positive aspects of a situation would be considered a form of cognitive coping, while engaging in substance abuse or physically distancing oneself from the source of stress would be conceptualized as behavioral coping. Another common approach involves distinguishing between approach and avoidance coping (Holohan and Moos, 1987; Roth and Cohen, 1986). This model suggests that coping involves alternating between approach, which involves attempts to integrate painful material, and avoidance, which involves attempts to protect oneself from a threatening event. Thus, approach allows for direct action in attempts to regulate stress, whereas avoidance serves to prevent negative emotions from becoming overwhelming, by allowing distance from the trauma and thereby reducing stress (Roth \& Cohen, 1986). Of importance to note, Moos (1995) suggests that cognitive/behavioral and approach/avoidance coping dimensions can be considered in combination when assessing and analyzing coping strategies. Specifically, to integrate these facets of coping, Moos proposes that the cognitive/behavioral construct reflects the "method" of coping, while the approach/avoidance distinction refers to the "focus" of coping.

Coping can refer both to strategies typically used in response to a variety of common stressors (i.e., individuals display particular coping styles) as well as to strategies anchored to aspects of a particular stressful event (i.e., individuals modulate the strategies used based on the particular stressor or trauma encountered). The experience of CSA might prompt the use of particular coping strategies across more general domains of functioning as well as in specific stressful situations. Consistent with this notion, Finkelhor and Browne (1985) proposed a model termed the Traumagenic Dynamics Model of CSA that accounts, in part, for the manner in which CSA might influence the development of coping strategies. This model posits that four dynamics explain the symptoms observed in sexual abuse victims: traumatic sexualization, betrayal, stigmatization, and powerlessness. A "traumagenic dynamic is an experience that alters a child's cognitive or emotional orientation to the world and causes trauma by distorting the child's selfconcept, worldview, or affective capacities" (Finkelhor, 1987; p. 354). Finkelhor suggests that victims may develop abuse-related schemas and coping strategies that are adaptive and reflect integration, but may be "dysfunctional in coping with a world where abuse is not the norm" (p. 355).

Coping effectively with sexual abuse is likely to occur in phases over time and involve the use of different strategies (Burgess and Holmstrom, 1976; Horowitz, 1986). Thus, it is reasonable to conclude that the adaptive outcomes associated with the coping process also will change over time. For example, if avoidance is adaptive in the short-term, victims who are able to employ this strategy effectively might evidence decreased levels of emotional distress. However, if long-term coping requires the integration of the abuse into existing schemas, increased distress might be expected during this phase, as an individual is required to examine the meaning of the trauma. Further, the dynamics of abuse are considered pro- 
cesses, rather than events, that create cognitive distortions (Finkelhor, 1987). These distortions are proposed to relate to the emotional and behavioral difficulties seen in both adult and child victims of CSA that must be understood in the context of the victim's life prior to, during, and following the abuse (Finkelhor, 1987).

\section{Coping with CSA: a review of the empirical literature}

Understanding the process of coping with trauma from a theoretical standpoint provides a foundation from which to examine coping with CSA on an empirical level. Empirical studies exploring the relationship between CSA and coping have been conducted in three primary ways: 1) investigations providing descriptive information regarding the coping strategies that victims employ in relation to their abuse experiences; 2) studies examining associations between various coping strategies and long-term correlates of abuse; and 3) studies examining coping as an intervening factor in the relationship between CSA and long-term outcomes. The present review synthesizes work in each of these domains. To gather pertinent articles examining coping with CSA, an initial search of the PsychINFO, PILOTS, ERIC, and Medline databases was conducted using keywords such as "coping" and "child sexual abuse." The reference sections of those articles identified in this search were examined to obtain additional studies not identified through the electronic searches. This strategy yielded a total of 39 published articles addressing adult coping with CSA. These studies have been grouped into the three main categories noted above: those that are primarily descriptive in nature $(n=11)$, those that examine the correlational associations between coping strategies and long-term functioning $(n=18)$, and those that examine coping as a mediator of the relationship between CSA and longterm outcomes $(n=10)$. What follows is a review of the studies in each of these areas.

\subsection{How do adult abuse victims cope with child abuse experiences?}

Many investigations of coping among adult CSA victims utilize qualitative research designs to describe the coping methods most often employed by CSA victims. Typically, these studies use open-ended interviews to assess coping, with later coding of responses into categories based upon the content of the interviews. Such studies vary in nature of the samples used, operationalization of CSA, and methods of assessing coping. Further, these studies are retrospective in design, involve adult female CSA victims, and use some form of semi-structured interview to assess sexual abuse, as well as the ways in which individuals coped with CSA, either at the time of the abuse or as an adult. Section 1 of Table 1 provides a summary of these investigations. Collectively, these studies indicate that CSA victims use a wide array of coping strategies, including cognitive (e.g., cognitive reappraisal, reframing, minimization, memory repression, distraction) and behavioral (e.g., avoidance, addictive behaviors) efforts to deal with their abuse experiences. For example, Brand, Warner, and Alexander (1997) found that adult incest victims recruited via newspaper advertisements used 19 different coping strategies, ranging from cognitive avoidance to behavioral sublimation. In a small sample of 11 adult women participating in counseling, Morrow and Smith (1995) identified two core coping strategies: 1) keeping from being overwhelmed by threatening emotions and 2) managing feelings of helplessness, powerlessness, and lack of control. Moreover, among 40 adult women recruited from electoral rolls in New Zealand, Perrott, Morris, Martin, and Romans (1998) proposed six main coping styles (e.g., deliberately suppressing, reframing, working through the abuse, seeking support, talking about the abuse as adults, and coping on own). Similarly, among 10 selfidentified resilient adult women who had experienced CSA, positive coping strategies, refocusing and moving on, active healing, and achieving closure were identified as processes that enabled women to effectively manage their negative emotions (Bogar \& Hulse-Killacky, 2006). Attempting to illuminate adaptive coping strategies, Himelein and McElrath (1996) examined females in their first year of college and found that four coping strategies emerged in resilient CSA victims: disclosure, minimization, positively reframing the abuse, and refusing to dwell on the past.

Illustrating changes in coping that may occur over time, DiPalma (1994) examined child and adult coping styles of 15 adult victims of incest who self-identified as "high functioning." Coping strategies used by these individuals during childhood included attempts to stop the abuse, avoidance, psychological escape, and compensation, while adult strategies involved breaking away from the past, cognitive coping, self-discovery, and revisiting the past (DiPalma, 1994). Oaksford and Frude (2003) also attempted to illustrate how the process of coping with CSA may evolve over time. Using semi-structured interviews, 11 adult female victims were asked about the coping strategies they used at the time of the abuse (i.e., immediate strategies) as well as coping used later in life (i.e., long-term strategies). Results suggested that some strategies were used only in the immediate aftermath of the abuse (e.g., psychological escape, physical resistance, and disclosure), whereas others served as long-term coping efforts (e.g., rumination, normalizing the abuse, and acquiring a sense of psychological control). Strategies that emerged as both enduring and prevalent included: wishful thinking, cognitive appraisal, downward comparison, and minimization. Overall, these findings suggest that sexual abuse victims report using a wide range of coping strategies both in the immediate aftermath of abuse and over the long-term, although the specific strategies used may differ substantially with time. As expected, for instance, coping responses used in the immediate aftermath of abuse appear to generally reflect avoidance behaviors whereas long-term coping strategies appear to reflect cognitive efforts to integrate the material.

In addition to describing CSA victims' typical coping responses, studies also have examined links between specific abuse characteristics and coping strategies. This is important because more severe or chronic abuse may increase the likelihood of using a particular coping strategy. For example, using a sample of 66 of college women, DiLillo, Long, and Russell (1994) compared intraversus extrafamilial sexual abuse victims on a standardized coping checklist and found that intrafamilial victims engaged in increased use of both problem-focused and emotion-focused coping strategies when compared to extrafamilial victims. Among undergraduate women, increased CSA severity also has been shown to predict greater use of maladaptive coping strategies such as withdrawing from others, acting out sexually or aggressively, and using alcohol or drugs (Filipas \& Ullman, 2006). A study of men and women recruited from multiple sources (college, outpatient, and inpatient) revealed that increased resistance during the abuse experience was associated with lower use of confrontive coping as an adult, and longer duration of abuse was associated with increased use of distancing (Steel, Sanna, Hammond, Whipple, \& Cross, 2004). Examining the construction of victims' life stories (i.e., narratives) in relation to coping strategies, Klein and JanoffBulman (1996) found that male and female undergraduates who placed blame on their perpetrator or others used more adaptive coping strategies. However, these authors assessed only cognitive coping strategies (avoiding dwelling on the abuse and overgeneralizing) without accounting for behavioral coping methods.

Studies of multitype maltreatment (i.e., experiencing more that one abuse type) can illuminate differences in coping between victims reporting various abuse types as well as how the experience of additional maltreatment types might influence the use of particular coping strategies. For instance, among college women reporting multiple forms of abuse (e.g., physical and sexual), Futa, Nash, Hansen, and Garbin (2003) found that all child abuse victims 
Table 1. Coping strategies employed by adult CSA victims: summary of study characteristics and empirical findings.

\begin{tabular}{|c|c|c|c|c|c|}
\hline \multirow[b]{2}{*}{ Study } & \multicolumn{3}{|c|}{ Definition of CSA } & & \multirow{2}{*}{$\begin{array}{l}\text { Major findings regarding descriptions of } \\
\text { coping strategies utilized by participants } \\
\text { with a history of CSA }\end{array}$} \\
\hline & $\begin{array}{l}\text { Size and source } \\
\text { of study sample }\end{array}$ & Nature of abusive acts & $\begin{array}{l}\text { Age difference } \\
\text { required }\end{array}$ & Measure of coping & \\
\hline
\end{tabular}

Section 1: How do adult abuse victims cope with child abuse experiences?

Hillace-

Abused "during child- NR

NR

hood by someone

(2006)

abuse victims;

recruited via re-

at three universi-

ties

Brand et al. 101 female incest

(1997) victims; newspa-

per ads

Abuse "in childhood or adolescence" by family member or ferrals and fliers someone older living in the home

DiLillo et al. 66 female col(1994)

lege students;

recruited from psychology department

DiPalma

(1994)

15 incest victims Self-id of "sexual

self-identified as

"high function-

ing"; snowball

technique

Futa et al.

(2003)

196 female undergraduates with a history of CPA,

CSA, both, or no

abuse

Himelein Study 1: 180

and female college

McElrath students; Study

2: 20 of Study

1 CSA victims

(put in high- vs.

low-adjustment

groups

Leitenberg et 828 female under-

al. (2004) graduates expe-

riencing 0-3+

types of abuse or

adverse events

Morrow

11 females re-

and Smith

cruited from

ing with CSA

victims

Perrott et al. 40 females; "ran-

(1998) domly selected

from electoral

rolls" in New

Zealand

"Any sexual activity"

ily member during

childhood or adoles

cence"

Any experience on

the Childhood

Experiences Form

(e.g., shown sexually

explicit material to

vaginal intercourse)

"Contact sexual experiences" (fondling, attempted intercourse,

intercourse) required

Self-id as 'abuse vic-
tim'; "varied from a

single incident ... to

... ongoing sadistic experience" ranging from non-genital contact to intercourse therapists work-
Under 13 5+ years; $10+$ years if victim aged 13-16

\section{NR}

NR

Under 15 5+ years

Under $14 \quad 4+$ years

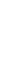

Study 1: Mastery Scale,

The Optimism Scale Study 2: semi-structured interview

\begin{tabular}{|c|c|c|c|}
\hline $\begin{array}{l}\text { Any sexual activity } \\
\text { involving genital con- } \\
\text { tact"; physical contact }\end{array}$ & Under 16 & $\begin{array}{l}5+\text { years or use } \\
\text { of physical } \\
\text { force }\end{array}$ & $\begin{array}{l}\text { Coping Strategies } \\
\text { Inventory }\end{array}$ \\
\hline
\end{tabular}

"Any unwanted sexual Under 16 "Someone older or bigger"

Ways of Coping
Checklist-Revised

Two semi-structured categorized as data were collected.

Qualitative interview transcribed and coded. 7 participants involved in focus groups on coping.

Qualitative interview involving open-ended questions, which were transcribed and coded
NR NR

Qualitative interview transcribed and coded.

Interview adapted from Incest History Questionnaire

Romans et al. 173 female CSA

(1999) victims and 178 controls; recruited from Otago

Women's Health

Survey study
“Any unwanted sexual

experience"
"Someone older or bigger"

Defense Style

Questionnaire, which assesses psychological coping strategies
Determinants of resiliency were interpersonal skills, competence, high self-regard, spirituality, and helpful life circumstances. Processes that facilitated resiliency were coping strategies, refocusing and moving on, active healing, and achieving closure

Most common coping strategies included: behavioral sublimation, avoidance of abuser, emotional expression, cognitive avoidance, dissociation, emotional suppression, verbal confrontation, rumination, withdrawal, addictive behaviors, and seeking social support.

Intrafamilial victims used more problemand emotion-focused coping (wishful thinking, self-blame, and self-isolation) and a greater number of additional strategies that did not load on either factor compared to extramfamilial victims.

Childhood coping included: attempts to stop abuse, avoidance, psychological escape, and compensation. Adult coping included: breaking away and creating own dreams, cognitive coping, self-discovery, and revisiting the past.

All groups used distancing and self-blame. CSA group used more self-isolation than $\mathrm{CPA}$ and the no abuse groups. CSA group low in social support seeking, tension reduction, problem-focused coping, and wishful thinking coping.

Study 1: Greater perceptions of internal control and higher unrealistic optimism predicted better adjustment. Study 2: Four long-term coping strategies used by resilient CSA victims: disclosure, minimization, positively reframing the abuse, and refusing to dwell on the past.

When coping with current stressor, disengagement (problem- and emotion-focused) but not engagement strategies positively correlated with number of abuse experiences.

Two strategies identified: (1) keeping from being overwhelmed by threatening feelings (e.g., reducing intensity, avoidance, release) and (2) managing helplessness, powerlessness, and lack of control (e.g., reframing, mastery, control other areas of life, rejecting power).

Identified six coping styles: deliberately suppressing, reframing, working through abuse, seeking support, talking about abuse, and coping on own. Reframing related to father/stepfather perpetrator and intercourse; avoidance or suppression related to attempted intercourse/intercourse; self-blame to chronic abuse or earlier age of onset.

CSA victims demonstrated increased use of following defenses: autistic fantasy, displacement, projection, passive aggressiveness, and acting out compared to nonvictims.

\section{Section 2: How do coping strategies relate to long-term outcomes of abuse?}

\begin{tabular}{|c|c|c|c|c|c|}
\hline $\begin{array}{l}\text { Bonanno et } \\
\text { al. (2003) }\end{array}$ & $\begin{array}{l}103 \text { females ( } 48 \\
\text { CSA victims, } \\
55 \text { non-abused) } \\
\text { aged } 11-25 \text { who }\end{array}$ & $\begin{array}{l}\text { “Abuse involved geni- } \\
\text { tal contact and/or } \\
\text { penetration; and per- } \\
\text { petrator was a family }\end{array}$ & NR & NR & $\begin{array}{l}\text { Repression: Taylor } \\
\text { Manifest Anxiety Scale } \\
\text { and Marlow-Crowne } \\
\text { Social Desirability Scale; }\end{array}$ \\
\hline
\end{tabular}

Non-disclosers of CSA tended to score as "repressors," while CSA disclosers reported greater dissociative scores. Repressive coping positively correlated with both positive 
Table 1. (continued)

\begin{tabular}{lcllc} 
& & Definition of CSA & \\
\cline { 4 - 5 } Study & $\begin{array}{c}\text { Size and source } \\
\text { of study sample }\end{array}$ & Nature of abusive acts & $\begin{array}{l}\text { Upper } \\
\text { age limit }\end{array}$ & $\begin{array}{c}\text { Age difference } \\
\text { required }\end{array}$ \\
\hline
\end{tabular}

\section{Section 2: How do coping strategies relate to long-term outcomes of abuse? (continued)}

$\begin{array}{ll}\text { Bonanno et } & \text { were part of an member..." } \\ \text { al. (2003) } & \begin{array}{l}\text { ongoing longi- } \\ \text { tudinal study of }\end{array} \\ \text { [cont.] } & \text { effects of CSA }\end{array}$

\begin{tabular}{|c|c|c|c|c|c|}
\hline $\begin{array}{l}\text { Brand and } \\
\text { Alexander } \\
(2003)\end{array}$ & $\begin{array}{l}101 \text { female incest } \\
\text { victims; recruit- } \\
\text { ed via newspa- } \\
\text { per ads. }\end{array}$ & $\begin{array}{l}\text { "Abuse in childhood } \\
\text { or adolescence by a } \\
\text { family member or } \\
\text { older co-residing in- } \\
\text { dividual" }\end{array}$ & NR & NR & Ways of Coping Checklist \\
\hline $\begin{array}{l}\text { Coffey et al. } \\
\text { (1996) }\end{array}$ & $\begin{array}{l}666 \text { females; ran- } \\
\text { domly selected } \\
\text { and sent ques- } \\
\text { tionnaires }\end{array}$ & $\begin{array}{l}\text { "Any sexual activity } \\
\text { involving physical } \\
\text { contact" }\end{array}$ & Under 16 & $\begin{array}{l}5+\text { years or use } \\
\text { of physical } \\
\text { force }\end{array}$ & $\begin{array}{l}\text { Coping Strategies } \\
\text { Inventory }\end{array}$ \\
\hline
\end{tabular}

$\begin{array}{cl}\begin{array}{c}\text { Filipas and } \\ \text { Ullman }\end{array} & \begin{array}{l}577 \text { female stu- } \\ \text { dents recruited } \\ \text { from) }\end{array} \\ & \text { from introduc- } \\ & \text { tory psychol- } \\ & \text { ogy/ criminal } \\ & \text { justice courses: } \\ & \text { 166 CSA; } 411 \\ & \text { non-CSA }\end{array}$

Griffing et al. 219 female doresponse discrepancy. Dissociation: adolescent version of Dissociative Experiences Scale

Sexual contact occurwith a perpetrator at least 5 years older

Positive response to items on Childhood Trauma Questionnaire
Under $145+$ years to assess cognitive and behavioral coping
Coping Strategies affective-autonomic ring prior to age 14 and/or intercourse)"
(2006) mestic violence victims; $40 \%$ reported CSA

Huang et al. 471 female Chi(2008) nese inmates Kenkel victims, recruit(1991) ed from treatment settings, ages 13-18

Johnson et al. 86 females "seek- "Unwanted or forced (2003) ing...therapy for symptoms related to...sexual abuse. fondling, oral sex Inventory -Short Form

NR NR Trait Coping Style Questionnaire

Ways of Coping Checklist (wording modified for age appropriateness)

\section{Under $135+$ years or $10+\quad$ Coping Strategies} if victim aged Inventory 13-16

NR

Self-reported physical

NR scribed as "extremely

Janofffemale undergraduates reporting physical, emotional, or sexual abuse; 23 controls.

Leitenberg et 54 female nurses "Any sexual experial. (1992) in New England responding to mailed questionnaires.

$\begin{array}{ll}\text { Murthi and } & 116 \text { college } \\ \text { Espelage } & \text { women report- } \\ \text { (2005) } & \begin{array}{l}\text { ing child sexual } \\ \text { abuse }\end{array}\end{array}$

Contact sexual experiences occurring before age 12 with someone older than 16 or with family member

Oaksford Phase II: 11 fe- "Broad definition... and Frude male undergrad- that included peer (2003) uates in the UK; abuse, but excluded Phase III: same experiences of mu11 CSA victims tual sexual exploration..."

Under 15 5+ years, Questionnaire designed minimum for study, with items age $16 \quad$ pertinent to CSA.

Under 12 Perpetrator older Ways of Coping than 16 Questionnaire

Phase II: Ways of Coping Checklist-Revised; interview
Major findings regarding descriptions of coping strategies utilized by participants with a history of CSA

and negative facial expressions; dissociative coping inversely correlated with emotional expression. Dissociation positively associated with PTSD, internalizing, and externalizing symptoms, whereas repression negatively correlated with internalizing and externalizing symptoms.

Emotion-focused coping used more than problem-focused. Avoidance and seeking social support positively associated with adult dysfunction, whereas distancing associated with less dysfunction (after controlling for abuse characteristics).

CSA victims reported greater use of disengagement coping and demonstrated greater psychological distress compared to controls. Disengagement related to Increased duration and level of sexual activity and accounted for unique variance in current psychological distress.

Increased CSA severity associated with more self-blame, maladaptive coping (withdrawing from people, acting out sexually, using alcohol or drugs, acting out aggressively), and PTSD symptoms. Maladaptive coping predicted PTSD and revictimization.

CSA associated with increased use of disengagement strategies (wishful thinking, self-criticism, social withdrawal) when compared to non-CSA. Disengaged coping associated with depression and low selfesteem

CSA and negative coping both predicted PTSD severity after controlling for personality characteristics

Wishful thinking most significant coping predictor of global distress. Tension-reduction and distancing related to increased distress; seeking social support related to increased therapist-rated psychopathology.

Approach positively correlated with passive aggressive and histrionic personality disorder (PD); avoidance positively correlated with PTSD severity and avoidant, dependent, borderline, paranoid, schizotypal and schizoid PD as well as CSA victims diagnosed with PTSD.

Avoiding dwelling on abuse and overgeneralizing associated with lower psychological distress. Abuse group reported increased psychological distress, though no differences in coping abilities. Use of "other" pronouns in narratives positively related to adaptive coping strategies.

Emotional suppression and denial most common coping methods. Denial, emotional suppression, cognitive rumination, and avoidance associated with greater psychological distress, after controlling for abuse characteristics.

Social support from family and friends was found to moderate associations between CSA and personal sense of loss associated with alexithymia and depression.

NR NR Phase III: semi-structured
Wider range of coping, problem-focused coping and self-blame related to poorer adjustment. Immediate strategies: psychological escapes, support, action-oriented, and cognitive appraisal. Long-term strategies: same as immediate, with addition of positive reframing. 
Table 1. (continued)

\begin{tabular}{|c|c|c|c|c|c|}
\hline \multirow[b]{2}{*}{ Study } & \multirow[b]{2}{*}{$\begin{array}{l}\text { Size and source } \\
\text { of study sample }\end{array}$} & \multicolumn{3}{|l|}{ Definition of CSA } & \multirow[b]{2}{*}{ Measure of coping } \\
\hline & & Nature of abusive acts & $\begin{array}{l}\text { Upper } \\
\text { age limit }\end{array}$ & $\begin{array}{l}\text { Age difference } \\
\text { required }\end{array}$ & \\
\hline \multicolumn{6}{|c|}{ Section 2: How do coping strategies relate to long-term outcomes of abuse? (continued) } \\
\hline $\begin{array}{l}\text { Sigmon et al. } \\
\text { (1996) }\end{array}$ & $\begin{array}{l}19 \text { male and } 58 \\
\text { female CSA } \\
\text { victims recruited } \\
\text { form local and } \\
\text { national support } \\
\text { groups }\end{array}$ & & NR & NR & \\
\hline $\begin{array}{l}\text { Silver et al. } \\
\text { (1983) }\end{array}$ & $\begin{array}{l}77 \text { female incest } \\
\text { victims; recruit- } \\
\text { ed using news- } \\
\text { papers, posters, } \\
\text { announcements }\end{array}$ & $\begin{array}{l}\text { "Explicit sexual con- } \\
\text { tact between a female } \\
\text { child and father or } \\
\text { other adult male } \\
\text { serving in father role" }\end{array}$ & NR & NR & $\begin{array}{l}\text { Self-assessment of } \\
\text { resolution of feelings; } \\
\text { search for meaning (2 } \\
\text { open-ended questions) }\end{array}$ \\
\hline $\begin{array}{l}\text { Ullman and } \\
\text { Filipas } \\
\text { (2005) }\end{array}$ & $\begin{array}{l}733 \text { male and } \\
\text { female students } \\
\text { recruited from } \\
\text { introduc- } \\
\text { tory psychology/ } \\
\text { criminal justice } \\
\text { courses; 167 CSA; } \\
566 \text { non-CSA }\end{array}$ & $\begin{array}{l}\text { Sexual contact occur- } \\
\text { ring prior to age } 14 \\
\text { with a perpetrator at } \\
\text { least } 5 \text { years older }\end{array}$ & Under 14 & $5+$ years & $\begin{array}{l}\text { Questionnaire designed } \\
\text { to assess cognitive and } \\
\text { behavioral coping }\end{array}$ \\
\hline $\begin{array}{l}\text { Ullman, } \\
\text { Townsend, } \\
\text { et al. (2007) }\end{array}$ & $\begin{array}{l}636 \text { community } \\
\text { women }\end{array}$ & $\begin{array}{l}\text { Unwanted sexual } \\
\text { experiences prior to } \\
\text { age } 18 \text { (distinguished } \\
\text { between CSA and } \\
\text { ASA) }\end{array}$ & Under 18 & NR & Brief COPE \\
\hline $\begin{array}{l}\text { Walsh, et al. } \\
(2007)\end{array}$ & $\begin{array}{l}73 \text { undergraduate } \\
\text { females recruit- } \\
\text { ed through fly- } \\
\text { ers and internet } \\
\text { postings }\end{array}$ & $\begin{array}{l}\text { Sexual abuse as indi- } \\
\text { cated by the Child- } \\
\text { hood Trauma Ques- } \\
\text { tionnaire }\end{array}$ & Under 16 & NR & Ways of Coping - Revised \\
\hline $\begin{array}{l}\text { Wright et al. } \\
(2007)\end{array}$ & $\begin{array}{l}60 \text { mothers with } \\
\text { sexual abuse his- } \\
\text { tories recruited } \\
\text { through flyers, } \\
\text { newspapers, and } \\
\text { internet postings }\end{array}$ & $\begin{array}{l}\text { Adult mothers who } \\
\text { had experienced } \\
\text { childhood sexual } \\
\text { abuse }\end{array}$ & NR & NR & $\begin{array}{l}\text { Coping Strategy Indicator; } \\
\text { open-ended questions } \\
\text { about resolution of CSA, } \\
\text { benefits of coping, and } \\
\text { meaning derived from } \\
\text { abuse }\end{array}$ \\
\hline
\end{tabular}

Major findings regarding descriptions of coping strategies utilized by participants with a history of CSA

Avoidance coping most commonly used strategy among CSA victims; avoidance coping related to increased anxiety, depression, and posttraumatic symptoms. Women endorsed greater use of emotion-focused coping whereas men endorsed greater acceptance.

Finding meaning associated with less distress, and increased social adjustment, self-esteem, and resolution of abusive experiences. Continued search for meaning associated with increased distress, impairment in social functioning, and lower self-esteem and resolution of abuse experiences.

Women who delayed disclosure had greater PTSD severity than those who disclosed sooner; for men, this relationship was nonsignificant. Among male and female abuse victims, maladaptive coping predicted increased PTSD after controlling for abuse characteristics.

Using SEM, negative social reactions of others and avoidant coping are strongest predictors of PTSD

Positive coping strategies (summary of problem-focused coping, seeking social support, and focusing on positive) associated with decreased likelihood of experiencing adult sexual coercion

Avoidant coping associated with more depressive symptoms; women who reported that abuse was unresolved were more likely to use avoidant coping; finding meaning in the experience was associated with less social isolation and better adjustment

Section 3: Do coping strategies mediate relations between CSA and adult adjustment?

\begin{tabular}{|c|c|c|c|c|c|}
\hline $\begin{array}{l}\text { Draucker } \\
(1995)\end{array}$ & $\begin{array}{l}149 \text { females; ques- } \\
\text { tionnaires sent } \\
\text { to clinicians }\end{array}$ & $\begin{array}{l}\text { Not specified; women } \\
\text { attending "sexual } \\
\text { abuse groups" in } 18 \\
\text { major metropolitan } \\
\text { areas }\end{array}$ & NR & NR & $\begin{array}{l}\text { The Cognitive Adaptation } \\
\text { Scale }\end{array}$ \\
\hline $\begin{array}{l}\text { Fortier et al. } \\
\text { (2009) }\end{array}$ & $\begin{array}{l}99 \text { female under- } \\
\text { graduates with a } \\
\text { history of CSA }\end{array}$ & $\begin{array}{l}\text { Sexual touching, kissing, } \\
\text { or oral, anal, or vaginal } \\
\text { intercourse with an in- } \\
\text { dividual } 5 \text { or more years } \\
\text { older before age of } 14 \text {, or } \\
\text { with someone } 10 \text { or more } \\
\text { years older if victim was } \\
14 \text { to } 17 \text { years, or any } \\
\text { of the aforementioned } \\
\text { activities experienced } \\
\text { against their will, regard- } \\
\text { less of the difference in } \\
\text { age or relationship to the } \\
\text { perpetrator }\end{array}$ & $\begin{array}{l}17 \text { or } \\
\text { under }\end{array}$ & $\begin{array}{l}5+\text { years if victim } \\
\text { was } 14 \text { or } \\
\text { younger, } 10+ \\
\text { years if victim } \\
\text { was } 14-17 \text { years } \\
\text { old, no age } \\
\text { difference if } \\
\text { experiences } \\
\text { were against } \\
\text { will of victim }\end{array}$ & $\begin{array}{l}\text { Coping Strategies } \\
\text { Inventory }\end{array}$ \\
\hline $\begin{array}{l}\text { Frazier et al. } \\
\text { (2004) }\end{array}$ & $\begin{array}{l}\text { 88-98 females; } \\
\text { presenting at an } \\
\text { ER for sexual } \\
\text { assault }\end{array}$ & $\begin{array}{l}\text { "Any sexual activity } \\
\text { they did not want to } \\
\text { happen" }\end{array}$ & Under 12 & NR & $\begin{array}{l}\text { Coping Strategies } \\
\text { Inventory; Religious } \\
\text { Coping Scale }\end{array}$ \\
\hline $\begin{array}{l}\text { Gibson and } \\
\text { Leitenberg } \\
(2001)\end{array}$ & $\begin{array}{l}106 \text { female under- } \\
\text { graduates, ex- } \\
\text { perienced adult } \\
\text { sexual assault } \\
\text { within past year }\end{array}$ & $\begin{array}{l}\text { CSA: "sexual experi- } \\
\text { ences" with physical } \\
\text { contact; Adolescent } \\
\text { sexual abuse (ASA): } \\
\text { "sexual victimiza- } \\
\text { tion" }\end{array}$ & $\begin{array}{l}\text { CSA: } \\
\text { Under } \\
\text { 12; ASA: } \\
\text { 14-17 }\end{array}$ & $\begin{array}{l}\text { CSA/ASA: } 5+ \\
\text { years or forced } \\
\text { sexual activity }\end{array}$ & $\begin{array}{l}\text { Coping Strategies } \\
\text { Inventory }\end{array}$ \\
\hline
\end{tabular}

Stigmatization and powerlessness directly related to meaning and indirectly related to guilt and social introversion. Finding meaning and sense of mastery related to less guilt and isolation in adulthood. Mastery related to decreased interpersonal victimization.

Avoidant coping mediated relationship between CSA and traumatic distress, which in turn, was associated with sexual revictimization in adulthood. Specifically, severity of CSA predicted use of avoidant coping strategies, which in turn predicted traumatic distress in adulthood. Increased traumatic distress was associated with increased risk for coercive sexual revictimization.

Positive life changes associated with use of approach coping and sense of control over recovery. Social support positively related to approach coping, control over recovery, precautions against future assault, and decreases in avoidant coping.

Disengagement related to increased psychological distress and PTSD symptoms. History of CSA related to disengagement and feelings of stigma and powerlessness in response to adult sexual assault. Stigma found to mediate relationship between history of CSA and use of disengagement. 
Table 1. (continued)

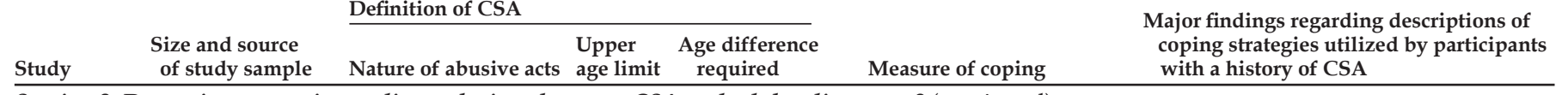

Section 3: Do coping strategies mediate relations between CSA and adult adjustment? (continued)

\begin{tabular}{|c|c|c|c|c|c|}
\hline $\begin{array}{l}\text { Guelzow et } \\
\text { al. (2002) }\end{array}$ & $\begin{array}{l}144 \text { female under- } \\
\text { graduates (44 } \\
\text { CSA, } 144 \text { non- } \\
\text { victims) }\end{array}$ & $\begin{array}{l}\text { Sexual contact; "any- } \\
\text { thing ranging from } \\
\text { playing 'doctor' to } \\
\text { sexual intercourse" }\end{array}$ & Under 16 & $\begin{array}{l}5+\text { years or no } \\
\text { consent, use } \\
\text { of force or } \\
\text { coercion }\end{array}$ & $\begin{array}{l}\text { Coping Inventory for } \\
\text { Stressful Situations }\end{array}$ \\
\hline $\begin{array}{l}\text { Merrill et al. } \\
(2003)\end{array}$ & $\begin{array}{l}547 \text { female U.S. } \\
\text { Navy recruits }\end{array}$ & $\begin{array}{l}\text { "Any sexual con- } \\
\text { tact... with a family } \\
\text { member or with a } \\
\text { non-family member" }\end{array}$ & Under 14 & $5+$ years & $\begin{array}{l}\text { How I Deal With Things } \\
\text { Scale }\end{array}$ \\
\hline
\end{tabular}

\begin{tabular}{|c|c|c|c|c|}
\hline $\begin{array}{l}\text { Merrill et al. } \\
(2001)\end{array}$ & $\begin{array}{l}\text { 4,098 female U.S. } \\
\text { Navy recruits, } \\
28 \%(N=1,134) \\
\text { experienced } \\
\text { CSA. }\end{array}$ & $\begin{array}{l}\text { Sexual kissing/touch- } \\
\text { ing; made to touch } \\
\text { sexual parts; oral, } \\
\text { anal, or vaginal inter- } \\
\text { course, anal or vagi- } \\
\text { nal penetration }\end{array}$ & Under 14 & $5+$ years \\
\hline $\begin{array}{l}\text { Runtz and } \\
\text { Schallow } \\
(1997)\end{array}$ & $\begin{array}{l}191 \text { female and } \\
110 \text { male under- } \\
\text { graduates, re- } \\
\text { porting physical } \\
\text { or sexual abuse }\end{array}$ & $\begin{array}{l}\text { "Sexual contact" } \\
\text { involving lack of } \\
\text { consent (determined } \\
\text { by age, power, victim } \\
\text { view as abusive or } \\
\text { negative) }\end{array}$ & $\begin{array}{l}\text { Under } 15 \\
\text { or lack of } \\
\text { consent }\end{array}$ & $\begin{array}{l}5+\text { years older } \\
\text { or } 10+\text { years if } \\
\text { between } 15-18\end{array}$ \\
\hline $\begin{array}{l}\text { Steel et al. } \\
(2004)\end{array}$ & $\begin{array}{l}285 \text { males and } \\
\text { females recruited } \\
\text { from non-patient } \\
\text { (college), psychi- } \\
\text { atric outpatient, } \\
\text { and psychiatric } \\
\text { inpatient settings }\end{array}$ & $\begin{array}{l}\text { "Unwanted or forced } \\
\text { sexual contact during } \\
\text { childhood or adoles- } \\
\text { cence" }\end{array}$ & Under 18 & NR \\
\hline $\begin{array}{l}\text { Wyatt and } \\
\text { Newcomb } \\
(1990)\end{array}$ & $\begin{array}{l}111 \text { females, } \\
\text { contacted by } \\
\text { random-digit } \\
\text { dialing of tele- } \\
\text { phones. }\end{array}$ & $\begin{array}{l}\text { "Sexual body contact," } \\
\text { including fondling } \\
\text { and attempted or } \\
\text { completed vaginal or } \\
\text { oral intercourse }\end{array}$ & Under 18 & $\begin{array}{l}5+\text { years or } \\
\text { contact not } \\
\text { desired or } \\
\text { involving } \\
\text { coercion }\end{array}$ \\
\hline
\end{tabular}

CSA indirectly related to global self-worth through paternal support. For CSA victims, paternal support indirectly related to global self-worth through its effects on emotionfocused coping.

Positive relationship between CSA severity and avoidant and self-destructive coping. Self-destructive coping related to dysfunctional sexual behavior and increased number of sex partners, and avoidance associated with increased sexual concerns and decreased numbers of sex partners

How I Deal With Things Self-destructive and avoidance coping posiScale tively related to psychological symptoms. Constructive coping negatively associated with symptomatology. Negative coping mediated relationship between abuse severity and adjustment.

Coping: How I deal with Expressing emotion and actively seeking Things change associated with positive psychological functioning. Self-destructive and avoidant coping associated with impaired psychosocial functioning. Mediating effects of social support only supported for CPA.

Ways of Coping

Questionnaire Attributional Style Questionnaire

The coping strategies of accepting responsibility and confrontive coping mediated relationships between specific abuse characteristics (i.e., relationship to perpetrator, force, age of onset, and frequency of abuse) and psychological distress.

Immediate negative responses to abuse and internal attributions
Coping strategies of immediate negative responses and internal attributions fully explained the impact of abuse characteristics (e.g., age of last abuse, duration, and psychological coercion) on long-term negative outcomes. evidenced a greater tendency to use distancing and self-blame to cope, whereas CSA victims engaged in self-isolation to a greater degree than did victims of child physical abuse (CPA) and nonvictims. In addition, CSA victims were found to be low in social support seeking, tension reduction, problem-focused coping, and wishful thinking. Among a large sample of undergraduate women reporting multiple forms of abuse or other adverse childhood experiences, Leitenberg, Gibson, and Novy (2004) found that as the number of abuse types increased, a corresponding increase in the use of disengagement (both problem- and emotion-focused) methods of coping with current stressors was observed, although no difference was found in use of engagement methods of coping. This suggests that increased trauma exposure might require victims to devote more effort to coping with stressors by distancing themselves cognitively and emotionally. However, as Aldwin (1993) notes, an increase in the utilization of coping strategies does not necessarily correspond to increased efficacy of coping.

In concert with current theories of coping with trauma, descriptive studies indicate that coping with childhood sexual trauma is a multifaceted and complex process that evolves over time. Consistent across these studies are results indicating that the experience of sexual trauma is often associated with the use of avoidant coping strategies, particularly in the short-term. In addition, many victims report the use of cognitive coping strategies later in life, which fits with trauma theories suggesting that integration is a critical strategy in the final phases of coping. These studies provide a foundation from which to understand coping with sexual trauma on an individual level and suggest that assessments of coping must not only encompass a wide variety of behavioral, cognitive, and emotional efforts, but also must be sensitive to changes in coping over time. Furthermore, these results provide insights into the range of coping strategies that victims may employ at different developmental stages (i.e., childhood versus adulthood), as well as factors that may relate to the use of particular strategies (e.g., relationship to perpetrator, severity, resistance during abuse, and duration of abuse, and multitype abuse).

Although descriptive studies provide useful initial information, they have several limitations. In particular, many qualitative studies utilize small sample sizes and identify a large number of coping strategies, some of which were only reported by a few individuals. These limitations suggest that these studies may not provide a representative assessment of the coping strategies typically used by CSA victims. Further, these studies rely on retrospective assessments of methods of coping at the time of the abuse and therefore may be influenced by errors in recall as well as distorted by current functioning. Although some consistencies in coping strategies are noted, the categorizations of coping differed greatly across studies, making direct comparisons difficult. None of these studies assessed male victims of CSA and, consequently, offer results that are not generalizable to more diverse populations.

\subsection{How do coping strategies relate to long-term outcomes of abuse?}

In addition to descriptive studies, researchers have also examined the relationship between specific types of coping and longterm outcomes. Section 2 of Table 1 provides a summary of the correlational studies. Some studies from Section 1 of Table 1 also are discussed here if associations between coping strategies and adjustment were examined. As noted previously, CSA is considered a "non-specific risk factor" for a range of detrimental outcomes (Putman, 2003; Romans et al., 1997). General psychological distress is the most commonly examined outcome of abuse 
found in the coping literature, followed closely by psychosocial outcomes such as PTSD, dissociation, depression, and interpersonal problems including sexual dysfunction and revictimization. One important outcome of CSA that is not included in the present study is physical health problems resulting from abuse (Finestone et al., 2000; Najman et al., 2007; Romans et al., 2002). This area has been excluded from the present review because few studies have specifically examined coping strategies in relation to physical pain and medical problems resulting from the abuse. Typically, correlational studies employ standardized checklists to investigate the relationship between coping and adult psychological adjustment, most often assessed using a symptom checklist. Similar to the descriptive approaches noted above, the majority (11 of 18) of the correlational studies examined female populations.

Much of the coping literature with CSA victims has documented heightened levels of psychological distress among these women (Klein and Janoff-Bulman, 1996; Oaksford and Frude, 2003). Avoidance and denial strategies appear to be commonly used and have repeatedly been linked to increased levels of self-reported distress and symptomatology (Brand and Alexander, 2003; Johnson and Kenkel, 1991; Leitenberg et al., 1992; Steel et al., 2004), even after controlling for abuse severity and characteristics (Brand and Alexander, 2003; Coffey et al., 1996; Leitenberg et al., 1992).

Although Oaksford and Frude (2003) found wide variation in coping strategies used by poorly and relatively well-adjusted victims, results suggested that well-adjusted individuals tended to utilize one or two coping strategies (e.g., seeking support), whereas poorly adjusted victims employed a wider variety of methods, perhaps stretching their efforts across both adaptive and maladaptive strategies in an unsuccessful attempt to deal with their abuse (Oaksford \& Frude, 2003). Research supports the importance and implications of finding meaning in childhood abuse experiences. For example, in a sample of 60 mothers reporting CSA experiences, Wright, Crawford, and Sebastian (2007) found that the cognitive coping strategy of finding meaning in the abuse experience was associated with less social isolation and better overall adjustment. Similarly, Silver, Boon, and Stones (1983) reported that for 77 adult incest victims, finding meaning in the abuse was related to lower psychological distress, better social adjustment, increased self-esteem, and resolution of the abuse experiences, compared to victims who reported that they were still searching for meaning. These authors suggest that continued search for meaning may be related to rumination about the events, and as such, may indicate that victims had not yet come to terms with their abuse-related issues.

Although most studies examining coping and adult adjustment have focused on global psychological distress as the primary outcome, some investigations have focused on more specific aspects of psychological functioning such as depression and posttraumatic stress. These findings indicate that CSA victims who employ avoidant (Sigmon et al., 1996; Wright et al., 2007) or disengagement (i.e., wishful thinking, self-criticism, and social withdrawal; Griffing Lewis, Chu, Sage, Jospitre, 2006) coping strategies tend to report increased depressive symptoms. More specifically, Wright and colleagues discovered that women who reported that their sexual abuse was unresolved were more likely to use avoidant coping strategies, which in turn, predicted greater depression. Additionally, Griffing and colleagues found that increased CSA severity predicted greater use of disengagement coping strategies (e.g., wishful thinking, self-criticism, and social withdrawal), which in turn predicted greater depression and lower self-esteem. Overall, these findings from college, treatment-seeking, incarcerated, and military samples suggest that CSA victims who use maladaptive coping strategies (e.g., avoidance) over the long term are likely to develop increased trauma symptoms (Filipas and Ullman, 2006; Huang et al., 2008; Johnson et al., 2003; Ullman and Filipas, 2005).
As might be expected given such findings, studies suggest that the coping strategy of seeking social support is associated with decreased symptomatology in both adolescent (e.g., Bal, Crombez, Van Oost, \& Debourdeaudhuij, 2003) and adult victims (Filipas and Ullman, 2001; Murthi and Espelage, 2005). A key element in this relationship appears to be the response of the support network. For example, among child victims, a supportive relationship with the non-offending parent has been found to be predictive of psychological resilience, defined as social functioning comparable to non-victimized youths and the absence of clinically significant symptomatology (Spaccarelli \& Kim, 1995). Tremblay, Hebert and Piche (1999) illustrated that for both male and female sexually abused youth, stronger perceived social support was related to increased self-worth and lower symptomatology. Further, among college samples, CSA victims who received social support from family and friends were less likely to experience negative outcomes (Murthi \& Espelage, 2005). However, in some cases, seeking social support has been linked to increased distress. For instance, findings of heightened distress have been documented both via self-report measures administered to adult samples of incest victims (Brand \& Alexander, 2003) as well as via therapist-rated dysfunction among adolescents in treatment centers (Johnson \& Kenkel, 1991). However, in these samples it is possible that disclosure was met with negative responses, consistent with research suggesting that negative reactions to disclosure of adult sexual assault are associated with adverse consequences for the victims, whereas positive responses following disclosure are related to more adaptive outcomes (Filipas and Ullman, 2001; Ullman et al., 2007).

Himelein and McElrath (1996) suggest that increased perceptions of control and unrealistic optimism in general are predictive of better adjustment in both CSA victims and non-victims. It may be that, as a coping strategy, unrealistic optimism can "cushion the impact" of a stressor, thereby serving a protective function against later distress (Himelein \& McElrath, 1996). Similarly, Walsh, Blaustein, Grant-Knight, Spinazzola, and van der Kolk (2007) found that college women who employed positive coping strategies (e.g., problem-focused coping, seeking social support, and focus on the positive) and had an internal locus of control were less likely to experience a coercive sexual assault as an adult. Further, using data from a seven year longitudinal study of the effects of sexual abuse, Bonanno, Noll, Putnam, O'Neill, \& Trickett (2003) examined repressive coping and dissociative tendencies in relation to trauma symptomatology and abuse disclosure in a sample of female adolescents and young adults. Findings revealed that among 48 sexually abused participants who had been referred by child protective services agencies, non-disclosers of CSA tended to score as "repressors," whereas CSA disclosers reported greater dissociation. Further, repressive coping was positively correlated with both positive and negative facial expressions and negatively associated with internalizing and externalizing symptoms. Conversely, dissociative coping was negatively correlated with emotional expression and positively associated with PTSD, internalizing, and externalizing symptoms.

In general, these correlational studies suggest that CSA victims employ increased use of avoidant or emotion-focused coping strategies both in the immediate aftermath of abuse and over time, and such methods are related to greater psychological distress in adulthood. However, the causal nature of this relationship remains unclear. CSA victims may use avoidant strategies to deal with their negative emotions related to CSA. Conversely, it also is possible that the use of avoidant strategies predated victimization and contributes to persistent emotional distress. Correlational studies also highlight the potential effectiveness of particular coping strategies (e.g., social support) on adult adjustment, as well as the potential importance of strategies that may be specific to the experience of trauma (e.g., finding meaning in the abuse). Importantly, however, 
there appear to be certain contexts wherein strategies typically conceptualized as adaptive (e.g., searching for meaning in the abuse, disclosure of CSA experiences) are actually associated with more negative outcomes. These examples highlight the contextual nature of coping as well as the complexity involved in researching coping and suggest a need to glean a thorough understanding of the context and functionality of the coping method employed.

Despite the value of current investigations of long-term coping with CSA, such studies also suffer from limitations. For example, some investigations assess general coping styles (i.e., typical coping with a wide range of potential stressors) in relation to adult adjustment (e.g., Walsh et al., 2007), whereas others measure coping specifically with the early abuse experience and later adult adjustment (e.g., Oaksford and Frude, 2003; Sigmon et al., 1996). Further, among the studies that measure coping specifically with the abuse, many ask only about current coping with the abuse, ignoring the dynamic nature of coping with abuse over time (e.g., Bonanno et al., 2003). Thus, depending on the instrument chosen and accompanying instructions, researchers may arrive at starkly contrasting conclusions about relations between coping methods and adjustment among adult victims of CSA. Finally, much of the research in this area provides only a bivariate account of the relationship between CSA and adult adjustment, failing to take into account the complexity of the relationship of multiple factors that may contribute to the negative outcomes often experienced by CSA victims.

\subsection{Do coping strategies mediate relations between CSA and adult adjustment?}

A logical next step in the research on coping with CSA is to build upon the bivariate associations found in correlational studies by proposing models that include coping, among other factors, as a potential mediator of linkages between CSA and long-term outcomes. These studies typically propose that coping processes are among the key pathways by which abusive experiences may impact long-term adjustment. Specifically, abuse victims who use maladaptive coping strategies are hypothesized to evince increased adult adjustment difficulties. Many investigations employ Baron and Kenny's (1986) well-known procedures for testing mediation. In doing so, these mediational studies provide an opportunity to better illuminate the complexity of the relationship between CSA and long-term adjustment. Refer to Section 3 of Table 1 for a summary of the mediational studies.

Wyatt and Newcomb (1990) offered one of the earliest examinations of mediation by illustrating that immediate negative responses to the abuse and internal attributions related to the abuse mediated long-term adjustment by accounting for the impact of several abuse characteristics (age of last abuse, duration of abuse, psychological coercion) upon negative outcomes. In this study, the direct effects of these abuse characteristics were reduced after partialing the effects of coping responses. More recent investigations have revealed that strategies such as confrontive coping, accepting responsibility for the abuse, and internalizing the abuse experience mediate relationships between specific abuse characteristics (e.g., age of onset, duration, and resistance during the abuse) and psychological distress as adults (Steel et al., 2004). More specifically, women who resisted during the abuse were less likely to use confrontive coping (i.e., aggressive efforts to cope that involve a degree of risk taking and hostility), and increased use of confrontive coping was positively associated with greater psychological distress. Additionally, women with longer abuse durations were more likely to internalize the abuse experience (i.e., blame themselves), which was associated with increased psychological distress. Similarly, women who reported being older when the abuse began accepted more responsibility for the abuse and reported increased psychological distress as a result.
Expanding on the psychological distress literature, researchers have examined both coping strategies and distress as intervening factors in the relationship between CSA and adult revictimization. Specifically, trauma symptoms have been suggested to increase the risk of revictimization in victims of CSA (Messman-Moore et al., 2005; Messman-Moore et al., 2009; Sandberg et al., 1999) and coping strategies have been proposed to account, in part, for these relationships. Thus, Fortier, DiLillo, Messman-Moore, Peugh, DeNardi and Gaffey (2009) examined 99 female college students with a history of CSA using a meditational model in which severity of revictimization in adulthood was hypothesized to be a result of the impact of avoidant coping on trauma symptoms. Using MacKinnon, Lockwood, Hoffman, West, and Sheets' (2002) criteria for testing mediation, findings suggested that severity of CSA predicted use of avoidant coping, which was in turn predictive of increased trauma symptoms in adulthood (Fortier et al., 2009). Trauma symptoms were then associated with increased severity of coercive sexual revictimization. Thus, long-term use of avoidant coping strategies may partially explain the association between psychological distress and increased risk of revictimization in female CSA victims.

Mediational studies have often incorporated Finkelhor and Browne's (1985) "traumagenic dynamics model," which is a framework for conceptualizing the long-term effects of abuse. As noted earlier, this model proposes four dynamics to understand the impact of abuse experiences on functioning: powerlessness, betrayal, stigmatization, and traumatic sexualization. Draucker (1995) used this framework to examine the relationship of traumagenic dynamics, coping in the form of Taylor's (1983) cognitive adaptation (e.g., search for meaning, mastery, self-enhancement), and the long-term correlates of CSA in adult women participating in group therapy for victims of sexual abuse. The traumagenic dynamics of stigmatization and powerlessness had direct statistical effects on the cognitive coping task of meaning, and both had indirect effects on guilt and social introversion. Further, the ability to find meaning and regain a sense of mastery was related to better psychological adjustment in adulthood (Draucker, 1995).

Gibson and Leitenberg (2001) also used the traumagenic model to examine the relationship between CSA, traumagenic dynamics, and disengagement and engagement methods of coping in a sample of undergraduate females. Rather than examine coping as a mediator, it was proposed that the traumagenic dynamics would mediate the relationship between a history of CSA and methods of coping. Thus, coping was examined as an outcome variable in this study. Results revealed that stigmatization mediated the relationship between CSA and the use of disengagement methods of coping. More specifically, CSA was indirectly related to increased use of disengagement coping strategies, through its effects of feelings of stigmatization.

Several researchers have included abuse severity in their mediational frameworks. For example, Merrill, Guimond, Thomsen, and Milner (2003) examined the relationship between abuse severity and coping in a large sample of female U.S. Navy recruits reporting a history of CSA. Results indicated that women who experienced more severe CSA used increased avoidant and selfdestructive coping strategies in comparison to victims of less severe CSA. Further, self-destructive methods of coping were positively related to dysfunctional sexual behavior and number of sexual partners. Moreover, CSA was indirectly related to increased levels of sexual concerns and decreased numbers of sexual partners through its effects on avoidant coping strategies.

A common construct included in many mediational studies is social support. Investigators have demonstrated that both social support and coping mediate the relationship between CSA and adult adjustment (e.g., Frazier et al., 2004; Guelzow et al., 2002; Merrill et al., 2001; Runtz and Schallow, 1997; Wyatt and Newcomb, 1990). Representative of this work is a study by Runtz and 
Schallow (1997), who reported that the effects of abuse severity on long-term adjustment in a sample of undergraduate women were completely accounted for by social support and coping. Although social support emerged as the primary mediator in this relationship, the mediational effects of coping remained significant.

Researchers have also examined social support in the form of parental support following CSA. Investigating paternal support as well as coping, Guelzow et al. (2002) found that for female CSA victims attending college, paternal support was indirectly related to long-term functioning (i.e., global self-worth) through the use of emotion-focused coping strategies, suggesting that increased paternal support may buffer victims from the impact of CSA, thereby increasing overall self-worth. In contrast to these findings, Merrill et al. (2001) demonstrated that for a large sample of female Navy recruits, the relationship between adult adjustment and abuse severity was largely mediated by coping strategies, but that victims' perceptions of both maternal and paternal support did not contribute either directly or indirectly to adult functioning. Characteristics of the study samples may account for these discrepant findings. More specifically, paternal approval may be an important factor in the psychological adjustment of college students due to the importance that fathers place on education (Tannen, 1990; Turbiville and Marquis, 2001).

Although seemingly counterintuitive, coping and social support also have been examined in models that include the concept of positive changes following CSA. Positive changes refer to improvements in self (e.g., greater ability to take care of self), strengthened relationships (e.g., relationship with family), positive life philosophy or spirituality (e.g., greater sense of purpose in life), and stronger sense of empathy (e.g., greater concern for others in a similar situation; Frazier et al., 2004). In the more general trauma literature, approximately $50-60 \%$ of trauma victims note at least one positive life change following the traumatic event. Among adult female sexual assault victims presenting to emergency rooms (36\% of whom reported a history of CSA), greater social support was related to increased positive life changes over time, and this relationship was mediated by positive coping strategies (Frazier et al., 2004). Specifically, control over the recovery process almost entirely mediated the relationship between social support and positive life changes.

In summary, studies exploring the mediational role of coping in victims' long-term adjustment suggest that coping may indeed explain, in part, the variability in outcomes associated with a history of CSA. Thus, CSA may promote particular coping strategies that may, in turn, be related to different outcomes. The use of avoidant or self-destructive coping strategies may help explain the negative long-term outcomes associated with CSA. Social support also emerges in the literature as a coping-related construct that may play a role in the relationship between CSA and adult adjustment. However, associations between social support and long-term outcomes are currently unclear, due to inconsistencies in findings across these studies. Further, because many studies include a number of potential mediating variables, direct comparisons of results are difficult to make, making replication a necessary future endeavor.

\section{Conclusions and future directions}

A review of the theoretical and empirical literature related to coping with sexual abuse provides a starting point in understanding the process of adjustment following CSA. Theoretical writings indicate that coping with sexual trauma is a prolonged process, involving different coping strategies at the various stages in abuse recovery. Further, theorists suggest several constructs of particular importance to adaptive coping with sexual trauma, such as finding meaning in the experience, and the need to integrate traumatic events into existing cognitive frameworks. In fact, descriptive investigations suggest that victims retrospectively report a variety of strategies that evolve and change as the phases of coping with trauma change. However, the lack of longitudinal research on the topic is a hindrance to forming such conclusions. Further, certain strategies, namely avoidance, show predictable associations with psychological functioning whereas others, such as finding meaning in the abuse and seeking social support, appear to be linked with more adaptive outcomes, although not universally. These findings indicate a need to consider specific strategies within the context of a larger process model of coping. For example, the longterm use of avoidant coping strategies is related to increased distress in adulthood, whereas cognitive coping strategies (e.g., finding meaning, mastery) are related to more adaptive outcomes later in life. Finally, mediational investigations support the role of coping as a possible intervening variable in the CSA-adjustment relationship. Although such research is in its early stages, data show that cognitive methods of coping (e.g., appraisals) and seeking social support are potential pathways between CSA and adult functioning whereas increased use of avoidant and self-destructive coping strategies mediate links between various abuse characteristics and poor adjustment in adulthood.

Despite the value of this information, several limitations plague the current body of research and many questions remain unanswered. As described in more detail below, limitations of this research include theoretical and methodological issues, as well as a gap between research and practice.

\subsection{Theoretical and measurement issues}

\subsubsection{Defining coping}

As evidenced in the Introduction, literature in this area has employed various definitions of coping, resulting in a somewhat amorphous construct that encompasses a variety of cognitive, emotional, and behavioral responses to stressors. For example, in addition to cognitive strategies, such as focusing on the positive and distraction, behaviors, such as substance abuse and risky sex, are sometimes conceptualized as coping strategies (e.g., Filipas and Ullman, 2006; Polusny and Follette, 1995; Ullman et al., 2005). However, not all researchers agree that such an expansive definition of coping is warranted. These same behaviors have other times been examined as maladaptive outcomes (e.g., Merrill et al., 2003; Ullman et al., 2005). Without a clear operational definition of coping, studies purporting to assess coping may not consistently measure the same construct, thus limiting comparisons across studies.

\subsection{Methodological issues}

In addition to definitional inconsistencies, the reliance on cross-sectional, between-subjects designs in this area is limiting. Although informative, such studies do not afford the opportunity to determine causal relationships (Tennen, Affleck, Armeli, \& Carney, 2000). For instance, it has frequently been found that psychological distress is positively associated with emotion-focused coping (Coyne \& Racioppo, 2000). However, even if Baron and Kenny's (1986) statistical conditions for mediation are met, in the absence of longitudinal data, it is impossible to determine whether emotion-focused coping causes or emanates from psychological distress. Although the former is implied in many studies, it is plausible that negative emotions actually elicit (rather than cause) such coping strategies (Coyne \& Racioppo, 2000). Because crosssectional studies, which rely on coping checklists, are unable to capture the evolving nature of coping over time, future work in this area would benefit from a longitudinal, developmentally sensitive approach. One way of addressing these concerns is to employ a process-oriented approach that incorporates daily assessment methods of coping (e.g., Bolger and Schilling, 1991; Caspi et al., 1987; Clark and Watson, 1988; Marco and Suls, 1993; Rehm, 1987; Tennen et al., 2000). Such methods address many of the concerns associated with retrospective reporting (e.g., recall biases) and permit recording fluctuations in emotions alongside methods 
of coping (Tennen et al., 2000). These abilities are important given findings that retrospective accounts of coping are not equivalent to assessment at the time of a stressor or to daily accounts of coping (Smith, Leffingwell, \& Ptacek, 1999).

There are also those methodological limitations that are endemic to the larger body of CSA research, such as the lack of consistency in definitions used to establish the occurrence of sexual abuse (Haugaard, 2000). Many investigations include participants who merely self-identify as "victims" or vary in the nature of the characteristics used to operationalize CSA. Such differences affect not only the incidence and prevalence of abuse, but may result in differing portrayals of the nature and type of coping used by victims. There are also a number of issues regarding retrospective reports of abuse, including the potential for distorted recall and concerns regarding the reconstructive nature of autobiographical memory (Loftus, 1980; Schwarz and Sudman, 1994). Moreover, the utilization of college samples of CSA victims, who are almost always entirely female, limits the generalizability of results from these studies, both in terms of gender and SES. Hence, increased efforts to include broader community and clinical samples are needed to improve generalizability of findings.

\subsubsection{Measurement of coping}

Related to definitional issues in the coping literature, few attempts have been made to link the assessment of coping with trauma theory. In particular, it is questionable whether general coping checklists, designed for broad classes of stressors, are applicable to studies of CSA, given that such measures do not assess the coping processes thought to be most relevant to trauma victims (e.g., meaning, controllability, cognitive integration of the abuse; Aldwin, 1993; Horowitz, 1986; Kleber and Brown, 1992). Furthermore, checklists do not consider important contextual factors, such as the circumstances and effectiveness of the coping strategies employed (Coyne \& Racioppo, 2000) or "how much" one coped (Compas, Connor-Smith, Saltzman, Thomsen, \& Wadsworth, 2001; see Coyne and Gottlieb (1996) for a thorough discussion on the use of coping checklists). In some circumstances, victims may report increased reliance on maladaptive strategies due to limited alternatives. Children, for example, may not be able to physically escape their abusive situations, which could understandably lead to avoidant coping strategies. Other victims, however, may have expanded resources, yet rely on ineffective strategies nonetheless. Accordingly, future research will benefit from the development of coping instruments (e.g., semi-structured interviews) that incorporate concepts hypothesized to be specific to trauma and assessing factors related to the quality of coping efforts.

\subsubsection{Is coping a mediating or moderating construct?}

Coping has been most often examined as a mediator between CSA and adult functioning. However, the role that coping plays in this relationship warrants further consideration, given the common misuse and misunderstanding of the terms "mediator" and "moderator" (Baron and Kenny, 1986; Holmbeck, 1997). Investigators often fail to make correct distinctions between the terms mediator and moderator (Holmbeck, 1997), which can influence the selection of appropriate statistical analyses. Mediators are often conceptualized as being produced by the independent variable, and, in turn, are thought to be causally related to the dependent variable (e.g., Shadish \& Sweeney, 1991). Moderators, in contrast, are variables that affect the direction and/or strength of the relationship between an independent and dependent variable (Baron and Kenny, 1986; Holmbeck, 1997).

Holmbeck (1997) outlined several difficulties with the use of mediator and moderator variables in the literature, including the use of "idiosyncratic definitions" of these terms, describing a presumed mediator using the conceptualization for a moderator or vice versa, using improper diagrammatic representations of these processes, and applying inappropriate analytic procedures when testing for ef- fects (Holmbeck, 1997). Holmbeck highlights coping in his critique, arguing that investigators often fail to provide an adequate rationale for hypothesizing that coping and other process variables function as mediators. Temporally, this conceptualization may seem intuitively correct; however, the manner in which many authors present coping in mediational models may be better described as a moderational process, in that outcomes associated with a stressor may vary as a function of the nature of the coping strategies employed.

Theoretically, coping may serve either a mediating or moderating role. More specifically, CSA may engender a certain type of coping, which in turn contributes to long-term functioning, and the long-term effects of CSA also may vary as a function of a number of factors, one of which is coping. Some authors have explicitly tested these possibilities. For example, Merrill et al. (2001) describe and test coping both as a mediator and moderator of adult adjustment. These authors conclude that coping may in fact serve both functions. However, studies that thoroughly and accurately assess the mediating and moderating functions of coping with CSA are rare, and as noted by Holmbeck (1997), many researchers have incorrectly applied these labels.

\subsubsection{The limited range of outcome and intervening variables}

As this review illustrates, most studies of coping focus on psychological distress as a primary outcome variable despite indications that CSA has been linked to a wide array of positive and negative outcomes (Bonanno et al., 2003; Putman, 2003; Romans et al., 1997). In addition to concentrating on maladaptive outcomes, it also is important to take into account individually-relevant goals as a means of assessing whether coping processes impact adaptive functioning as well (Coyne \& Racioppo, 2000). For example, a victim's goals may include the establishment of satisfying interpersonal relationships, steady employment, and self-sufficiency - few of which have been explored as outcomes of adaptive coping. Furthermore, theoretically relevant moderating constructs have previously been viewed merely as confounding or nuisance variables in studies of coping. For example, demographic factors, such as age, SES, and ethnicity, have been treated as covariates without considering the possible interactive effects of these variables (e.g., Guelzow et al., 2002; Leitenberg et al., 2004; Merrill et al., 2001). Gender often has been ignored in CSA research through an almost exclusive focus on female participants (e.g., Walker, Carey, Mohr, Stein, \& Seedat, 2004). This omission is significant because gender and gender-related variables (e.g., perceived power, status) may interact with a variety of factors to influence the coping process (Banyard \& Graham-Bermann, 1993).

\subsubsection{The gap between research and practice}

A goal of coping research should be to inform clinical practice, for coping strategies represent potential targets for therapeutic intervention (Folkman and Lazarus, 1988; Roth and Cohen, 1986). Although the studies reviewed here provide support for the role of coping in the process of adjustment following CSA, little effort has been made to link this area of research to intervention possibilities. For example, a review of treatments for sexual abuse victims suggest that few treatments have targeted important factors, including "coping deficits" as a part of the intervention (Chard, Weaver, \& Resick, 1997). An exception to this trend is the work of Chard et al. (1997) whose Cognitive Processing Therapy for Sexual Abuse (CPT-SA; Chard, 1997) has been found to reduce abuserelated cognitive distortions in a sample of adult female CSA victims (Owens, Pike, \& Chard, 2001). Similarly, Cloitre (1998) describes an intervention termed Skills Training in Affect and Interpersonal Regulation (STAIR). She contends that affect dysregulation is one pathway through which CSA may impact coping processes (Cloitre, 1998). More specifically, sexual abuse may interfere with the development of appropriate affect regulation abilities, therefore predisposing victims of CSA to an over reliance on avoidant coping strategies (e.g., dissociation, substance abuse; Briere, 1992). Consequently, STAIR targets victims' abilities to identify and manage distressing emotions (Cloitre, 1998). 
Although these approaches are not framed explicitly within a coping perspective, to the extent that cognitive distortions and affect regulation are related to coping strategies, components of such interventions may ultimately have a positive impact on coping processes. These efforts begin to bridge the gap between research and practice; however, in order to advance knowledge translation in the field of coping with CSA, findings from the coping literature must be incorporated more explicitly into the development and empirical evaluation of interventions for adult sexual abuse victims. Opportunities for this integration should increase as the two research areas grow and evolve.

In summary, despite the accumulating body of information addressing adult coping in response to CSA, several important areas remain unexplored. For example, although the literature suggests that coping is a potentially important factor to consider when evaluating the long-term outcomes associated with CSA, there is little information about how factors, such as gender and SES, may moderate this association. In addition, little is known about the process of coping with CSA across various developmental periods. Hence, longitudinal designs that establish the temporal sequencing of CSA, coping, and psychological functioning are needed to demonstrate causation within a mediational framework and to better understand how victims cope across the lifespan. Finally, ongoing efforts are needed to integrate our evolving understanding of how victims cope with CSA, with the development of empirically supported interventions for adult victims.

\section{References}

Aldwin, 1993 - C. Aldwin, Coping with traumatic stress, PTSD Research Quarterly 4 (1993), pp. 1-3.

Bal et al., 2003 S. Bal, G. Crombez, P. Van Oost, and I. Debourdeaudhuij, The role of social support in well-being and coping with selfreported stressful events in adolescents, Child Abuse and Neglect $\mathbf{2 7}$ (2003), pp. 1377-1395.

Banyard and Graham-Bermann, $1993 \downarrow$ V. L. Banyard and S. A. Graham-Bermann, Can women cope? A gender analysis of theories of coping with stress, Psychology of Women Quarterly 17 (1993), pp. 303-318.

Baron and Kenny, 1986 R. M. Baron and D. A. Kenny, The moderator-mediator variable distinction in social psychological research: Conceptual, strategic, and statistical considerations, Journal of Personality and Social Psychology 51 (1986), pp. 1173-1182.

Beitchman et al., 1992 J. H. Beitchman, K. J. Zucker, J. E. Hood, G. A. DaCosta, D. Akman, and E. Cassavia, A Review of the long-term effects of child sexual abuse, Child Abuse \& Neglect 16 (1992), pp. 101-118.

Bennett et al., 2000 S. E. Bennett, H. M. Hughes, and D. A. Luke, Heterogeneity in patterns of child sexual abuse, family functioning, and long-term adjustment, Journal of Interpersonal Violence 75 (2000), pp. 134-157.

Bogar and Hulse-Killacky, 2006 C. B. Bogar and D. Hulse-Killacky, Resilience determinants and resiliency processes among female adult survivors of childhood sexual abuse, Journal of Counseling and Development 84 (2006), pp. 318-327.

Bolger and Schilling, $1991-$ N. Bolger and E. Schilling, Personality and the problems of everyday life: The role of neuroticism in exposure and reactivity to daily stressors, Journal of Personality 59 (1991), pp. 335-386.

Bonanno, 2005 G. A. Bonanno, Resilience in the face of potential trauma, Current Directions in Psychological Science 14 (2005), pp. 135-138.

Bonanno et al., 2003 G. A. Bonanno, J. G. Noil, F. W. Putnam, M. $\mathrm{O}^{\prime}$ Neill, and P. K. Trickett, Predicting the willingness to disclose childhood sexual abuse from measures of repressive coping and dissociative tendencies, Child Maltreatment 8 (2003), pp. 302-318.

Brand and Alexander, 2003 B. L. Brand and P. C. Alexander, Coping with incest: The relationships between recollections of childhood coping and adult functioning in female survivors of incest, Journal of Traumatic Stress 16 (2003), pp. 285-293.

Brand et al., 1997 B. Brand, S. C. Warner, and P. C. Alexander, Coping with incest in adult female survivors, Dissocation 10 (1997), pp. 3-10.

Briere, 1992 J. Briere, Child abuse trauma: Theory and treatment of the lasting effects, Sage, Newbury Park, CA (1992).

Burgess and Holmstrom, 1976 A. W. Burgess and L. L. Holmstrom, Coping behavior of the rape victim, American Journal of Psychiatry 133 (1976), pp. 413-418.

Caspi et al., 1987 A. Caspi, N. Bolger, and J. Eckenrode, Linking person and context in the daily stress process, Journal of Personality and Social Psychology 52 (1987), pp. 184-195.

Chard, 1997 Chard, K. M. (1997). Cognitive processing therapy for sexual abuse: A treatment manual. Manuscript in preparation.

Chard et al., 1997 K. M. Chard, T. L. Weaver, and P. A. Resick, Adapting cognitive processing therapy for child sexual abuse survivors, Cognitive and Behavioral Practice 4 (1997), pp. 31-52.

Clark and Watson, 1988 L. Clark and D. Watson, Mood and the mundane: Relations between daily life events and self-reported mood, Journal of Personality and Social Psychology 54 (1988), pp. 296-308.

Cloitre, 1998 M. Cloitre, Sexual revictimization: Risk factors and prevention. In: V. M. Follette and J. I. Ruzek, Editors, Cognitive-behavioral therapies for trauma, Guilford Press, New York (1998), pp. 278-304.

Coffey et al., 1996 P. Coffey, H. Leitenberg, K. Henning, T. Turner, and R. T. Bennett, The relation between methods of coping during adulthood with a history of childhood sexual abuse and current psychological adjustment, Journal of Consulting and Clinical Psychology $\mathbf{6 4}$ (1996), pp. 1090-1093.

Cohen, 1987 F. C. Cohen, Measurement of coping. In: S. V. Kasl and C. L. Coopers, Editors, Stress and health: Issues in research methodology, Wiley, New York (1987), pp. 283-305.

Compas et al., 2001 B. E. Compas, J. K. Connor-Smith, H. Saltzman, A. H. Thomsen, and M. E. Wadsworth, Coping with stress during childhood and adolescence: Problems, progress, and potential in theory and research, Psychological Bulletin 127 (2001), pp. 87-127.

Conte and Berliner, $1988-$ J. R. Conte and L. Berliner, The impact of sexual abuse on children: empirical findings. In: L. E. Walker, Editor, Handbook on sexual abuse of children: Assessment and treatment issues, Springer, New York (1988), pp. 72-93.

Coyne and Gottlieb, 1996 J. C. Coyne and B. H. Gottlieb, The mismeasure of coping by checklist, Journal of Personality 64 (1996), pp. 959-991.

Coyne and Racioppo, 2000 J. C. Coyne and M. W. Racioppo, Never the twain shall meet? Closing the gap between coping research and clinical intervention research, American Psychologist 55 (2000), pp. 655-664.

DiLillo et al., 1994 D. K. DiLillo, P. J. Long, and L. M. Russell, Childhood coping strategies of intrafamilial and extrafamilial female sexual abuse victims, Journal of Child Sexual Abuse 3 (1994), pp. 45-65.

DiPalma, 1994 L. M. DiPalma, Patterns of coping and characteristics of high-functioning incest survivors, Archives of Psychiatric Nursing 8 (1994), pp. 82-90.

Draucker, 1995 C. B. Draucker, A coping model for adult survivors of childhood sexual abuse, Journal of Interpersonal Violence 10 (1995), pp. 159-175.

Elliott and Briere, $1992>$ D. M. Elliott and J. Briere, Sexual trauma among professional women: Validating the Trauma Symptom Checklist-40, Child Abuse and Neglect 16 (1992), pp. 391-398.

Elliott and Briere, 1995 D. M. Elliott and J. Briere, Posttraumatic stress associated with delayed recall of sexual abuse: A general population study, Journal of Traumatic Stress 3 (1995), pp. 629-648.

Fergusson et al., $2008>$ D. M. Fergusson, J. M. Boden, and L. J. Horwood, Exposure to childhood sexual and physical abuse and adjustment in early adulthood, Child Abuse and Neglect 32 (2008), pp. 607-619.

Filipas and Ullman, $2001-$ H. H. Filipas and S. E. Ullman, Social reactions to sexual assault victims from various support sources, Violence and Victims 16 (2001), pp. 673-692.

Filipas and Ullman, 2006 H. H. Filipas and S. E. Ullman, Child sexual abuse, coping responses, self-blame, posttraumatic stress disor- 
der, and adult sexual revictimization, Journal of Interpersonal Violence 21 (2006), pp. 652-672.

Finestone et al., $2000>$ H. M. Finestone, P. Stenn, F. Davies, C. Stalker, R. Fry, and J. Koumanis, Chronic pain and health care utilization in women with a history if childhood sexual abuse, Child Abuse and Neglect 24 (2000), pp. 547-556.

Finkelhor, $1987 \rightarrow$ D. Finkelhor, The trauma of child sexual abuse: Two models, Journal of Interpersonal Violence 2 (1987), pp. 348-366.

Finkelhor, 1990 D. Finkelhor, Early and long-term effects of child sexual abuse: An update, Professional Psychology: Research and Practice $\mathbf{2 0}$ (1990), pp. 325-330.

Finkelhor, 1994 D. Finkelhor, Current information on the scope and nature of child abuse, The Future of Children 4 (1994), pp. 31-53.

Finkelhor and Browne, $1985>$ D. Finkelhor and A. Browne, The traumatic impact of child sexual abuse: A conceptualization, American Journal of Orthopsychiatry 55 (1985), pp. 530-541.

Finkelhor et al., $1990>$ D. Finkelhor, G. T. Hotaling, I. Lewis, and C. Smith, Sexual abuse in a national survey of adult men and women: Prevalence characteristics, and risk factors, Child Abuse \& Neglect 14 (1990), pp. 14-28.

Folkman and Lazarus, $1980 \triangleright$ S. Folkman and R. S. Lazarus, An analysis of coping in a middle-aged community sample, Journal of Health and Social Behavior 21 (1980), pp. 219-239.

Folkman and Lazarus, 1988 S. Folkman and R. S. Lazarus, Coping as a mediator of emotion, Journal of Personality and Social Psychology 54 (1988), pp. 466-475.

Fortier et al., 2009 M. A. Fortier, D. DiLillo, T. L. Messman-Moore, J. Peugh, K. A. DeNardi, and K. J. Gaffey, Child sexual abuse and revictimization: The mediating role of coping and trauma symptoms, Psychology of Women Quarterly 33 (2009), pp. 308-320.

Frazier et al., $2004>$ P. Frazier, T. Tashiro, M. Berman, M. Steger, and J. Long, Correlates of levels and patterns of positive life changes following sexual assault, Journal of Consulting and Clinical Psychology $\mathbf{7 2}$ (2004), pp. 19-30.

Futa et al., 2003 K. T. Futa, C. L. Nash, D. J. Hansen, and C. P. Garbin, Adult survivors of childhood abuse: An analysis of coping mechanisms used for stressful childhood memories and current stressors, Journal of Family Violence 18 (2003), pp. 227-239.

Gibson and Leitenberg, 2001 L. E. Gibson and H. Leitenberg, The impact of child sexual abuse and stigma on methods of coping with sexual assault among undergraduate women, Child Abuse $\mathcal{E}$ Neglect 25 (2001), pp. 1343-1361.

Goodman et al., 1997 L. A. Goodman, S. D. Rosenberg, K. Mueser, and R. E. Drake, Physical and sexual assault history in women with serious mental illness: Prevalence, correlates, treatment, and future research directions, Schizophrenia Bulletin 23 (1997), pp. 685-696.

Griffing et al., 2006 S. Griffing, C. S. Lewis, M. Chu, R. Sage, T. Jospitre and L. Madry et al., The process of coping with domestic violence in adult survivors of child sexual abuse, Journal of Child Sexual Abuse 15 (2006), pp. 23-41.

Guelzow et al., $2002-$ J. W. Guelzow, P. F. Cornett, and T. M. Dougherty, Child sexual abuse victims' perception of paternal support as a significant predictor of coping style and global self-worth, Journal of Child Sexual Abuse 11 (2002), pp. 53-61.

Haugaard, $2000 \triangleright$ J. J. Haugaard, The challenge of defining child sexual abuse, American Psychologist 55 (2000), pp. 1036-1039.

Himelein and McElrath, $1996>$ M. J. Himelein and J. V. McElrath, Resilient child sexual abuse survivors: Cognitive coping and illusion, Child Abuse \& Neglect 20 (1996), pp. 747-758.

Holohan and Moos, 1987 C. J. Holohan and R. H. Moos, Personal and contextual determinants of coping strategies, Journal of Personality and Social Psychology 52 (1987), pp. 946-955.

Holmbeck, 1997 G. N. Holmbeck, Toward terminological, conceptual, and statistical clarity in the study of mediators and moderators: Examples from the child-clinical and pediatric psychology literatures, Journal of Consulting and Clinical Psychology 65 (1997), pp. 599-610.

Horowitz, 1986 M. Horowitz, Stress response syndromes, Basic Books, New York (1986).

Huang et al., 2008 G. Huang, Y. Zhang, S. Momartin, X. Huang, and L. Zhao, Child sexual abuse, coping strategies, and lifetime posttrau- matic stress disorder among female inmates, International Journal of Prisoner Health 4 (2008), pp. 54-63.

Jacobsen and Herald, $1990 \triangleright$ A. Jacobsen and C. Herald, The relevance of childhood sexual abuse to adult psychiatric inpatient care, Hospital and Community Psychiatry 147 (1990), pp. 1547-1552.

Johnson and Kenkel, 1991 B. K. Johnson and M. B. Kenkel, Stress, coping, and adjustment in female adolescent incest victims, Child Abuse \& Neglect 15 (1991), pp. 293-305.

Johnson et al., 2003 D. M. Johnson, T. C. Sheahan, and K. M. Chard, Personality disorders, coping strategies, and posttraumatic stress disorder in women with histories of childhood sexual abuse, Journal of Child Sexual Abuse 12 (2003), pp. 19-39.

Kendall-Tackett et al., $1993 \rightarrow$ K. A. Kendall-Tackett, L. M. Williams, and D. Finkelhor, Impact of sexual abuse on children: a review and synthesis of recent empirical studies, Psychological Bulletin 113 (1993), pp. 164-180.

Kleber and Brown, $1992 \rightarrow$ R. J. Kleber and D. Brown, Coping with trauma: Theory, prevention, and treatment, Swets \& Zeitlinger B. V, Amsterdam (1992)

Klein and Janoff-Bulman, 1996 I. Klein and R. Janoff-Bulman, Trauma history and personal narratives: Some clues to coping among survivors of child abuse, Child Abuse \& Neglect 20 (1996), pp. 45-54.

Lazarus and Folkman, $1984-$ R. S. Lazarus and S. Folkman, Stress, appraisal, and coping, Springer, New York (1984).

Leitenberg et al., $2004 \longrightarrow$ H. Leitenberg, L. E. Gibson, and P. L. Novy, Individual differences among undergraduate women in methods of coping with stressful events: The impact of cumulative childhood stressors and abuse, Child Abuse E Neglect 28 (2004), pp. 181-192.

Leitenberg et al., 1992 H. Leitenberg, E. Greenwald, and S. Cado, A retrospective study of long-term methods of coping with having been sexually abused during childhood, Child Abuse \& Neglect 16 (1992), pp. 399-407.

Loftus, 1980 E. F. Loftus, Memory, Addison-Wesley, Reading, MA (1980).

MacKinnon et al., 2002 D. P. MacKinnon, C. M. Lockwood, J. M. Hoffman, S. G. West, and V. Sheets, A comparison of methods to test mediation and other intervening variable effects, Psychological Methods 7 (2002), pp. 83-104.

Marco and Suls, 1993 - C. Marco and J. Suls, Daily stress and the trajectory of mood: Spillover, response assimilation, contrast, and chronic negative affectivity, Journal of Personality and Social Psychology 64 (1993), pp. 1053-1063.

McClure et al., 2008 F. H. McClure, D. V. Chavez, M. D. Agars, M. J. Peacock, and A. Matosian, Resilience in sexually abused women: Risk and protective factors, Journal of Family Violence 23 (2008), pp. 81-88.

Merrill et al., 2003 - L. L. Merrill, J. M. Guimond, C. J. Thomsen, and J. S. Milner, Child sexual abuse and number of sexual partners in young women: The role of abuse severity, coping style, and sexual functioning, Journal of Consulting and Clinical Psychology 71 (2003), pp. 987-996.

Merrill et al., 2001 L. L. Merrill, C. J. Thomsen, B. B. Sinclair, S. R. Gold, and J. S. Milner, Predicting the impact of child sexual abuse on women: The role of abuse severity, parental support, and coping strategies, Journal of Consulting and Clinical Psychology 69 (2001), pp. 992-1006.

Messman-Moore et al., 2005 T. L. Messman-Moore, A. L. Brown, and L. E. Koelsch, Posttraumatic symptoms and self-dysfunction as consequences and predictors of sexual revictimization, Journal of Traumatic Stress 18 (2005), pp. 253-261.

Messman-Moore et al., 2009 - T. L. Messman-Moore, R. M. Ward, and A. L. Brown, Substance use and PTSD symptoms impact the likelihood of rape and revictimization in college women, Journal of Interpersonal Violence 24 (2009), pp. 499-521.

Mitchell et al., 1996 D. Mitchell, C. G. Grindel, and C. Laurenzo, Sexual abuse assessment on admission by nursing staff in general hospital psychiatric settings, Psychiatric Services 47 (1996), pp. 159-164.

Moos, 1995 R. H. Moos, Development and applications of new measures of life stressors, social resources, and coping responses, European Journal of Psychological Assessment 11 (1995), pp. 1-13. 
Morrow and Smith, 1995 S. L. Morrow and M. L. Smith, Constructions of survival and coping by women who have survived childhood sexual abuse, Journal of Counseling Psychology 42 (1) (1995), pp. 24-33.

Murthi and Espelage, 2005 M. Murthi and D. L. Espelage, Childhood sexual abuse, social support, and psychological outcomes: A loss framework, Child Abuse and Neglect 29 (2005), pp. 1215-1231.

Najman et al., 2007 J. M. Najman, M. L. T. Nguyen, and F. M. Boyle, Sexual abuse in childhood and physical and mental health in adulthood: An Australian population study, Archives of Sexual Behavior 36 (2007), pp. 666-675.

Neumann et al., 1996 D. A. Neumann, B. M. Houskamp, V. E. Pollock, and J. Briere, The long term sequelae of childhood sexual abuse in women: A meta-analytic review, Child Maltreatment 1 (1996), pp. 6-16.

Oaksford and Frude, $2003>$ K. Oaksford and N. Frude, The process of coping following child sexual abuse: A qualitative study, Journal of Child Sexual Abuse 12 (2003), pp. 41-72.

Owens et al., 2001 G. P. Owens, J. L. Pike, and K. M. Chard, Treatment effects of cognitive processing therapy on cognitive distortions of female child sexual abuse survivors, Behavior Therapy 32 (2001), pp. 413-424.

Perrott et al., 1998 K. Perrott, E. Morris, J. Martin, and S. Romans, Cognitive coping styles of women sexually abused in childhood: A qualitative study, Child Abuse \& Neglect 22 (1998), pp. 1135-1149.

Polusny and Follette, $1995>$ M. A. Polusny and V. M. Follette, Longterm correlates of child sexual abuse: Theory and review of the empirical literature, Applied and Preventive Psychology 4 (1995), pp. 143-166.

Putman, 2003 F. W. Putman, Ten-year research update review: Child sexual abuse, Journal of the American Academy of Child and Adolescent Psychiatry 42 (2003), pp. 269-278.

Read, 1997 J. Read, Child abuse and psychosis: A literature review and implications for professional practice, Professional Psychology $\mathbf{2 8}$ (1997), pp. 448-456.

Rehm, 1987 L. Rehm, Mood, pleasant events, and unpleasant events: Two pilot studies, Journal of Consulting and Clinical Psychology 46 (1987), pp. 854-859.

Romans et al., 2002 S. Romans, C. Belaise, J. Martin, E. Morris, and A. Raffi, Childhood abuse and later medical disorders in women: An epidemiological study, Psychotherapy and Psychosomatics 71 (2002), pp. 141-150.

Romans et al., 1999 S. E. Romans, J. L. Martin, and E. Morris, Defense styles in women who have experienced childhood sexual abuse: A comparative community study. In: L. M. Williams and V. L. Banyard, Editors, Trauma and memory., Sage Publications, Thousand Oaks, CA (1999).

Romans et al., 1997 S. Romans, J. Martin, and P. Mullen, Childhood sexual abuse and later psychological problems: Neither necessary, sufficient nor acting alone, Criminal Behavior and Mental Health 7 (1997), pp. 327-338.

Roth and Cohen, 1986 S. Roth and L. J. Cohen, Approach, avoidance, and coping with stress, American Psychologist 41 (1986), pp. 813-819.

Runtz and Schallow, 1997 M. G. Runtz and J. R. Schallow, Social support and coping strategies as mediators of adult adjustment following childhood maltreatment, Child Abuse \& Neglect 21 (1997), pp. 211-226.

Sandberg et al., 1999 D. A. Sandberg, A. I. Matorin, and S. J. Lynn, Dissociation, posttraumatic symptomatology, and sexual revictimization: a prospective examination of mediator and moderator effects, Journal of Traumatic Stress 12 (1999), pp. 127-138.

Schwarz and Sudman, 1994 N. Schwarz and S. Sudman, Autobiographical memory and the validity of retrospective reports, SpringerVerlag, New York (1994).

Shadish and Sweeney, $1991>$ W. R. Shadish and R. B. Sweeney, Mediators and moderators in meta-analysis: There's a reason we don't let dodo birds tell us which psychotherapies should have prizes, Journal of Consulting and Clinical Psychology 59 (1991), pp. 883-893.

Sigmon et al., 1996 S. T. Sigmon, M. P. Greene, K. J. Rohan, and J. E. Nichols, Coping and adjustment in male and female survi- vors of child sexual abuse, Journal of Child Sexual Abuse 5 (1996), pp. 57-76.

Silver et al., 1983 - R. L. Silver, C. Boon, and M. H. Stones, Searching for meaning in misfortune: Making sense of incest, Journal of Social Issues 39 (1983), pp. 81-102.

Smith et al., 1999 R. E. Smith, T. R. Leffingwell, and J. T. Ptacek, Can people remember how they coped? Factors associated with discordance between same-day and retrospective reports, Journal of Personality and Social Psychology 76 (1999), pp. 1050-1061.

Spaccarelli and Kim, $1995-$ S. Spaccarelli and S. Kim, Resilience criteria and factors associated with resilience in sexually abused girls, Child Abuse \& Neglect 19 (1995), pp. 1171-1182.

Steel et al., 2004 J. Steel, L. Sanna, B. Hammond, J. Whipple, and H. Cross, Psychological sequelae of childhood sexual abuse: Abuse-related characteristics, coping strategies, and attributional style, Child Abuse and Neglect 28 (2004), pp. 785-801.

Tannen, $1990-\mathrm{D}$. Tannen, Gender differences in topical coherence: Creating involvement in best friends' talk, Discourse Processes 13 (1990), pp. 73-90.

Taylor, $1983 \rightarrow$ S. E. Taylor, Adjustment to threatening events: A theory of cognitive adaptation, American Psychologist 38 (1983), pp. 1161-1173.

Tennen et al., $2000>$ H. Tennen, G. Affleck, S. Armeli, and M. A. Carney, A daily process approach to coping: Linking theory, research, and practice, American Psychologist 55 (2000), pp. 626-636.

Tremblay et al., $1999 \checkmark$ C. Tremblay, M. Hebert, and C. Piche, Coping strategies and social support as mediators of consequences in child sexual abuse victims, Child Abuse \& Neglect 23 (1999), pp. 929-945.

Trickett et al., 1997 P. K. Trickett, A. Reiffman, L. A. Horowitz, and F. W. Putman, Characteristics of sexual abuse trauma and the prediction of developmental outcomes. In: D. C. S. Toth, Editor, Rochester Symposium on Developmental Psychopathology: Developmental perspectives on trauma vol. 8, University of Rochester, Rochester, NY (1997), pp. 289-314.

Turbiville and Marquis, $2001>$ V. P. Turbiville and J. G. Marquis, Father participation in early education programs, Topics in Early Childhood Special Education 21 (2001), pp. 223-231.

Ullman and Filipas, 2005 S. E. Ullman and H. H. Filipas, Gender differences in social reactions to abuse disclosures, post-abuse coping, and PTSD of child sexual abuse survivors, Child Abuse and Neglect 29 (2005), pp. 767-782.

Ullman et al., 2005 S. E. Ullman, H. H. Filipas, S. M. Townsend, and L. L. Starzynski, Trauma exposure, posttraumatic stress disorder and problem drinking in sexual assault survivors, Journal of Studies on Alcohol 66 (2005), pp. 610-619.

Ullman et al., 2007 S. E. Ullman, S. M. Townsend, H. H. Filipas, and L. L. Starzynski, Structural model of the relations between assault severity, social support, avoidance coping, self-blame, and PTSD among sexual assault survivors, Psychology of Women Quarterly 31 (2007), pp. 23-37.

Walker et al., $2004-$ J. L. Walker, P. D. Carey, N. Mohr, D. J. Stein, and S. Seedat, Gender differences in the prevalence of childhood sexual abuse and in the development of pediatric PTSD, Archives of Women's Mental Health 7 (2004), pp. 111-121.

Walsh et al., $2007 \rightarrow$ K. Walsh, M. Blaustein, W. Grant-Knight, J. Spinazzola, and B. A. van der Kolk, Resilience factors in the relationship between child sexual abuse and adult revictimization, Journal of Child Sexual Abuse 16 (2007), pp. 1-17.

Wright et al., 2007 M. O. Wright, E. Crawford, and K. Sebastian, Positive resolutions of childhood sexual abuse experiences: The role of coping, benefit-finding, and meaning-making, Journal of Family Violence 22 (2007), pp. 597-608.

Wyatt and Mickey, 1987 G. E. Wyatt and M. Mickey, Ameliorating the effects of child sexual abuse: An exploratory study of support by parents and others, Journal of Interpersonal Violence 2 (1987), pp. 403-414.

Wyatt and Newcomb, 1990 G. E. Wyatt and M. Newcomb, Internal and external mediators of women's sexual abuse in childhood, Journal of Consulting and Clinical Psychology 58 (6) (1990), pp. 758-767. 